Technological University Dublin

DƯBLIN

ARROW@TU Dublin

Articles

Crest: Centre for Research in Engineering

Surface Technology

2015-06-07

\title{
Effect of the Condensation of Hybrid Organic-Inorganic sol-gel Materials on the Optical Properties of Tripan Blue
}

\author{
Craig Hicks \\ CREST, FOCAS Institute, Technological University Dublin \\ Muhammad Morshed \\ CREST, FOCAS Institute, Technological University Dublin \\ Garrett Melia \\ CREST, FOCAS Institute, Technological University Dublin
}

See next page for additional authors

Follow this and additional works at: https://arrow.tudublin.ie/cenresart

Part of the Physical Sciences and Mathematics Commons

\begin{abstract}
Recommended Citation
This Article is brought to you for free and open access by the Crest: Centre for Research in Engineering Surface Technology at ARROW@TU Dublin. It has been accepted for inclusion in Articles by an authorized administrator of ARROW@TU Dublin. For more information, please contact arrow.admin@tudublin.ie, aisling.coyne@tudublin.ie, gerard.connolly@tudublin.ie.
\end{abstract}

C. Hicks et al., Opt. Mater. (2015) Effect of the condensation of hybrid organic-inorganic sol-gel materials on the optical properties of tripan blue optmat.2015.06.010. doi:10.1016/j.optmat.2015.06.010

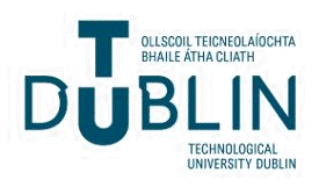




\section{Authors}

Craig Hicks, Muhammad Morshed, Garrett Melia, Killian Barton, Brendan Duffy, and Mohamed Oubaha 


\title{
Effect of the condensation of hybrid organic-inorganic sol-gel materials on the optical properties of tripan blue
}

\author{
Craig Hicks, Muhammad Morshed, Garrett Melia, Killian Barton, Brendan Duffy, Mohamed Oubaha* \\ Centre for Research on Engineering Surface Technology (CREST), FOCAS Institute, Dublin Institute of Technology, 13 Camden Row, Dublin 8, Ireland
}

\section{A R T I C L E I N F O}

Article history:

Received 9 April 2015

Received in revised form 7 June 2015

Accepted 7 June 2015

Available online $\mathrm{xxxx}$

Keywords:

Sol-gels

Hybrids

Organic dye

Photophysics

\begin{abstract}
A B S T R A C T
The work reported in this paper highlights the effect of sol-gel structures on the optical properties of a typical organic dye (Trypan Blue, TB). Three transition-metal-based hybrid sol-gel materials with different structures and morphologies were developed and characterised by TEM. The optical properties of TB were investigated by incorporating it in the different sol-gel materials and the UV-Visible spectra recorded in both liquid and solid state, in thin-coatings cured at temperatures in the range 100$150{ }^{\circ} \mathrm{C}$. These studies revealed two relevant results. First, the sol-gel morphology plays a critical role in the optical properties of the dye. The effect of the sol-gel host matrix on the optical properties of the dye is attributed to the steric hindrance of the nanostructures, themselves intimately dependant on the reactivity of the transition metal. For instance, the less condensed system showed the highest reactivity with the dye, while the more condensed system exhibited limited interaction with the dye, symbolised by a significant change or quasi-unchanged UV-Visible spectra, respectively. It is also shown that the increase of the condensation degree of the sol-gel coatings by heat-curing can dramatically alter the optical properties of the dye especially for the most condensed sol-gel systems. This has been attributed to proximity effects enabled by the further increase of the materials densities.

The results reported here aim to provide a better understanding of how material formulations can influence the optical properties of organic dyes and suggest that the structure of the host matrix along with the applied curing process have to be fully considered and assessed in the choice of organic dyes for a given application.
\end{abstract}

(ㄷ) 2015 Elsevier B.V. All rights reserved.

\section{Introduction}

Over the past decade, organic dyes have found applications in a number of scientific fields and industries including, colorants for plastics [1], inks [2], paints [3] and cosmetics [4], optical and lasers for telecommunications [5], sensing for medical diagnostic [6] and environmental monitoring [7] and electronics [8]. For most of these applications the essential objective of using organic dyes is to employ their intrinsic physical properties to provide advances in aesthetic or enable to highlight a physicochemical event that may occur due to an external stimulation.

In most cases, the dyes are dispersed in a liquid matrix, usually a polymer or a glass, and the resulting optical properties of the final materials associated to the dye behaviour. This approach is true when the role of the host material is limited to the dispersion and homogenisation of the dye within it. It is however more complex when interaction of both systems take place at the molecular level as this can result in the modification of the intrinsic physical

\footnotetext{
* Corresponding author.
}

properties of the dyes, the consequence of which could be a more or less significant alteration of the final properties of the system. It is thus essential to identify the effects of the possible physicochemical mechanisms, including both chemical reactions and degree of entrapment in a host matrix that can take place between both systems, which can alter the optical properties of the materials. To our knowledge, no study has so far aimed to highlight these phenomena.

The objective of this paper is to contribute in addressing this gap of knowledge and possibly initiate a number of fundamental studies in the field of dyes. For this, three hybrid sol-gel materials with different condensation capabilities, resulting in dramatically different structures and morphologies, are employed to highlight the effect of the structure of the host materials on the physicochemical properties of a selected organic dye, namely Trypan Blue (TB). The strategy to control the structure of sol-gel systems used in this work consists of controlling the degree of chelation of the employed transition metal. Similar studies outlining the effect of the ligand on the condensation of metal alkoxides have been performed before in pure inorganic alkoxide precursors 
$[9,10]$. However, our study differs in the nature of the employed precursors and in the development of dual sol-gel systems, containing both transition metal and organosilicate precursors. The structure of the host matrices are characterised by transmission electron microscopy (TEM). The optical properties of the dye are followed by UV-Visible absorption in liquid and solid states, as coatings deposited on glass substrates. The effect of the curing temperature of the fabricated coatings is also investigated and the obtained results are explained by correlating the structures and reactivity of the host materials and their interactions with the dye. Understanding of these parameters will help in the design of dyes with specific molecular structures targeting innovative optical materials for a wide range of applications.

\section{Experimental}

\subsection{Sol-gel synthesis}

The synthesis of the sol-gel matrix involved the formation of a stable and homogeneous sol obtained from the mixture of an organically modified silicate, the hybrid precursor 3-methacryloxy propyltrimethoxysilane (MAPTMS, $\mathrm{C}_{10} \mathrm{H}_{20} \mathrm{O}_{5} \mathrm{Si}$, Assay 99\% in methanol, Aldrich), zirconium (IV) n-propoxide ( $\mathrm{ZPO}, \mathrm{C}_{12} \mathrm{H}_{28} \mathrm{O}_{4} \mathrm{Zr}$, Assay $70 \%$ in propanol, Aldrich), and methacrylic acid as ligand (MAAH, $\mathrm{C}_{4} \mathrm{H}_{6} \mathrm{O}_{2}$, Assay $>98 \%$, Aldrich). As sketched in Fig. 1, the synthesis involves a three-step process. MAPTMS is initially pre-hydrolysed by employing a $\mathrm{HNO}_{3}$ aqueous solution $(0.1 \mathrm{M})$. At the same time, ZPO is chelated using MAAH. After $45 \mathrm{~min}$ of reaction both solutions are incorporated together. A release of heat is observed suggesting the formation of irreversible and fully stable chemical bonds. Following another $45 \mathrm{~min}$ of reaction, a second hydrolysis is performed to lead the hydrolysis degree to $50 \%$ of the total sol-gel reactive groups and allow the continuation of the polycondensation reactions. This hydrolysis degree is found to be very adequate as the obtained solutions exhibit viscosities comprised between those of water and light oils, thus allowing the formation of homogenous and transparent coatings with thicknesses in the micron scale range. In this study the molar ratio of the precursors have been altered in order to achieve nanomaterials with different morphologies and subsequently assess the influence of these morphologies on the UV-Visible absorption of a selected organic dye. To this end, the relative proportion of ZPO against MAAH was altered, while keeping the amount of MAPTMS constant. The molar contents of the three developed formulations are: 10:2.5:2.5 (material A), 10:2.5:0.625 (material B) and 10:2.5:0 (material C).

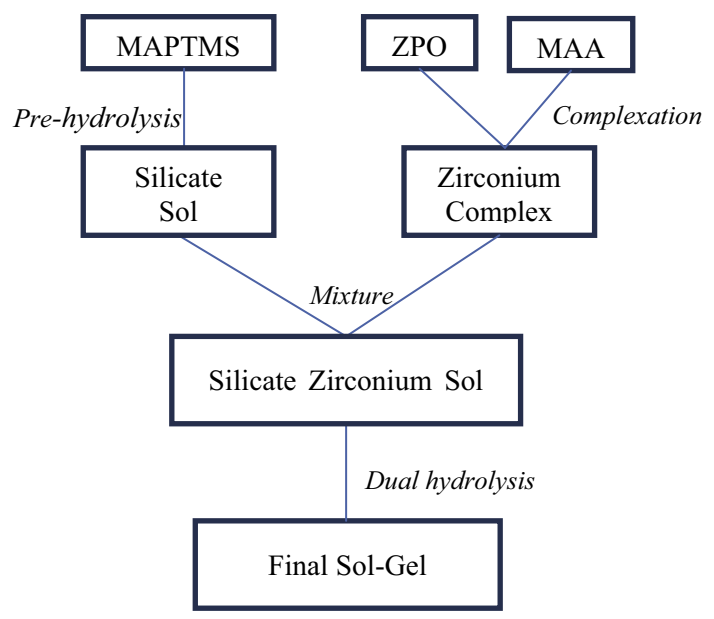

Fig. 1. Flow chart for the preparation of the hybrid sol-gel materials.
Trypan blue (3,3'-[(3,3'-dimethyl-4,4'-biphenylylene) bis (azo)] bis(5-amino-4-hydroxy-2,7-naphthalenedisulfonic acid) is the selected dye in this study (Fig. 2). It is a symmetrical molecule containing amino, hydroxyl and sulfoxide groups grafted onto a naphtalene group itself linked to a benzyl group through an azo function, which was added as $1 \% \mathrm{~mol}$. against the transition metal at the end of the sol-gel synthesis.

\subsection{Characterisation techniques}

The UV-Visible absorption spectra $(200-800 \mathrm{~nm})$ were recorded using a Cary Varian 50 scan spectrophotometer with a resolution of $4 \mathrm{~cm}^{-1}$. The scan speed was $600 \mathrm{~nm} / \mathrm{min}$. Liquid samples were analysed using polypropylene cuvettes. Measurements of solid samples were recorded using thin coatings deposited by spin-coating of the different sol-gel solutions onto quartz slides and thermally stabilized at different temperature ranging from 100 to $150^{\circ} \mathrm{C}$ for $1 \mathrm{~h}$.

FTIR spectra of all coatings cured at the three different temperatures of interest were recorded using a Perkin Elmer GX instrument operating in the ATR mode within the $600-4000 \mathrm{~cm}^{-1}$.

Transmission electron microscopy (TEM) was performed on a TECNAI G2 20 Twin electron microscope in bright field mode at $200 \mathrm{kV}$. The sections were prepared using a Leica EM UC6 ultramicrotome cutter with a cryo-chamber (EM FC6).

\section{Results and discussion}

\subsection{TEM analysis of hybrid sol-gels}

Fig. 3 shows the TEM images of the three hybrid sol-gel materials. A progressive increase of the particle size can be observed as the degree of chelation of the zirconium atom is decreased. For material A, most of the particles are in the nanometre scale $(<10 \mathrm{~nm})$. The TEM image of material B indicates that it is relatively homogeneous and dense with a particle size varying from 10 to $200 \mathrm{~nm}$. However, the particle size of material $C$ is in the micron range with an apparent gradual decrease in the density from the centre to the surface, as observed by the change in the contrast of the image of the particle.

These observations suggest that the formulation of these three materials has a direct impact on the reactivity of the hybrid systems to the sol-gel hydrolysis and condensation reactions, as well as on the subsequent structure and morphology of the formed particles. In fact, the main difference between these materials resides in the degree of chelation of the zirconium atom, the role of which has been identified in previous studies in catalysing the formation of siloxane bonds and participating to the formation of the inorganic backbone of the material [11-13]. In material A, the ligand is added in a stoichiometric ratio against the zirconium precursor, resulting in preventing $50 \%$ of its propoxide groups to undergo hydrolysis and further participate to the condensation reactions. In material B, only $25 \%$ of the propoxide groups are chelated, suggesting that $75 \%$ of the remaining groups are free to undergo hydrolysis and subsequently contribute to the formation of the

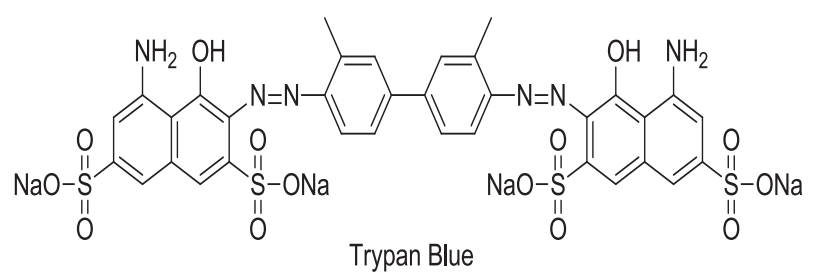



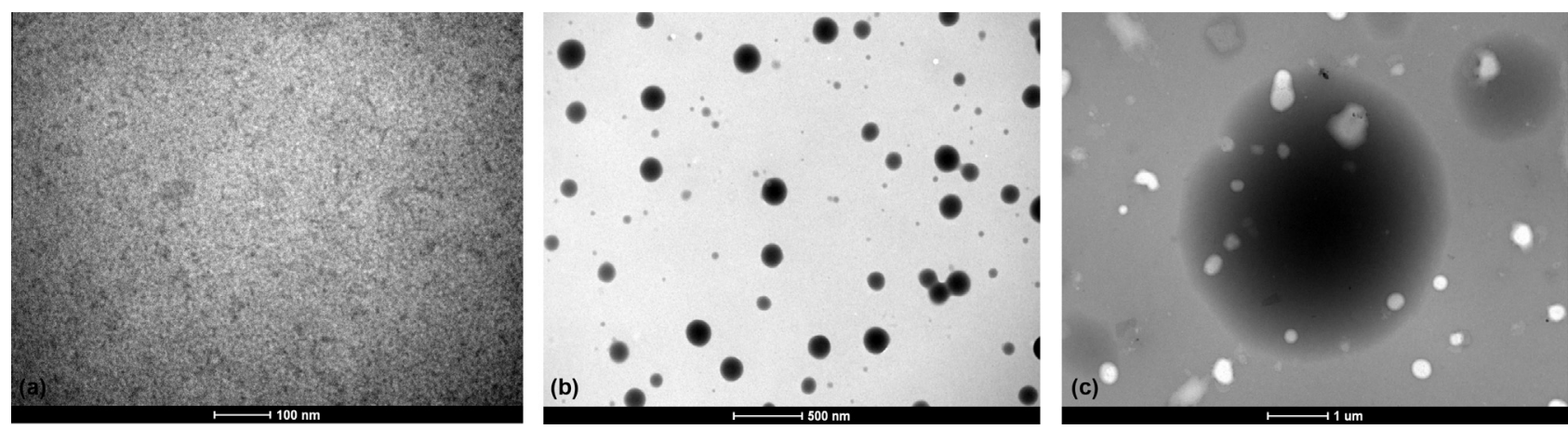

Fig. 3. TEM images of sol-gel formulation A (a), B (b) and C (c).

overall inorganic network. The inorganic reaction capability is thus increased compared to material A. More significantly, in material C, no ligand is utilised, meaning that $100 \%$ of the propoxide groups are able to participate to the sol-gel reactions. Furthermore, as the same hydrolysis rate was employed in the development of all materials, regardless of the ligand concentration, it can be deducted that the only parameter explaining the observed significant differences in nanostructures is associated to the ability of the transition metal to participate to the network formation.

\subsection{Thermal analysis}

As one of the objectives of this work is to investigate the effect of the curing temperature (in the range $100-150^{\circ} \mathrm{C}$ ) of the prepared materials onto the physical properties of the dye, it is essential to identify the thermal stability of the dye and the hybrid materials within the investigated temperature domain. For this purpose, TGA and DTA analyses were performed on the pure dye and on the three hybrid sol-gel materials as shown in Figs. 4 and 5 , respectively. As no difference was found on the three spectra recorded on the hybrid sol-gels, only one of them is represented here. One can observe that the pure dye has a large endothermic band centred at $70{ }^{\circ} \mathrm{C}$, which extent up to $150{ }^{\circ} \mathrm{C}$. This band is typical of entrapped water within highly hydrophilic systems. Three other endothermic bands are seen at 240,250 and $260{ }^{\circ} \mathrm{C}$, suggesting it is likely that the structure of the dye changes. Importantly for our study, apart from the removal of the adsorbed water, the decrease of the weight is around $4 \%$ of its initial weight at $150^{\circ} \mathrm{C}$, as shown by the TGA curve. Based on this, it is can be concluded that the dye exhibits a thermal stability within the temperatures used for curing the coatings. Therefore, any changes in the

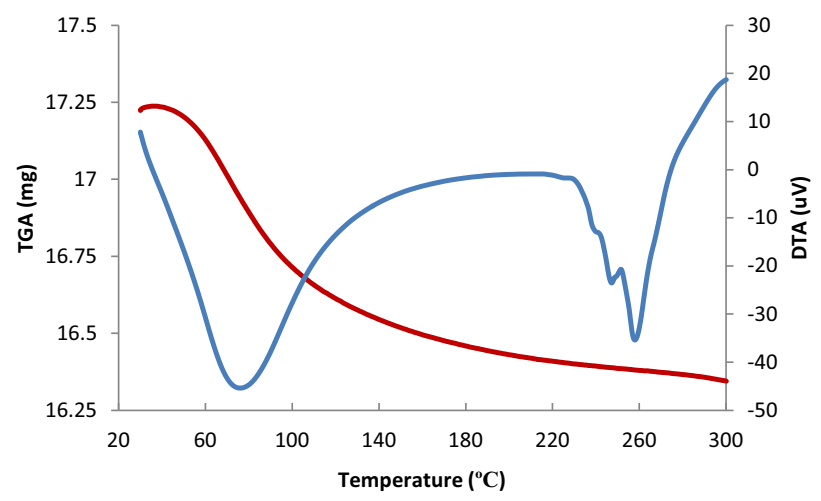

Fig. 4. DTA (blue) and TGA (red) spectra of tripan blue. (For interpretation of the references to colour in this figure legend, the reader is referred to the web version of this article.)

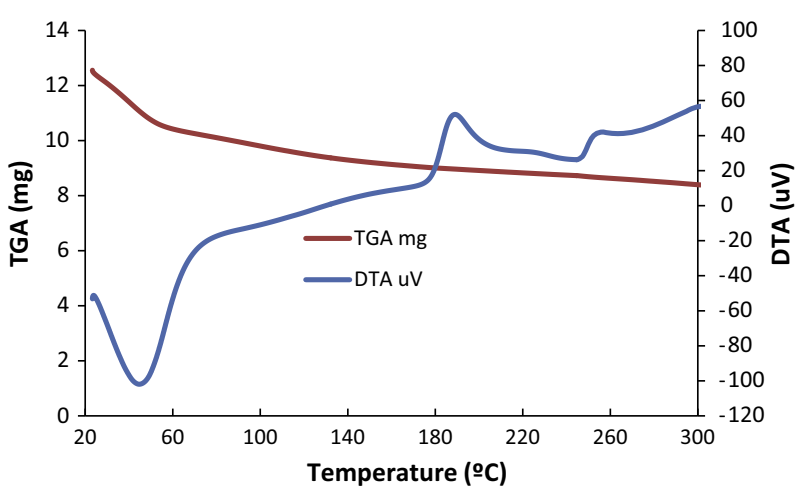

Fig. 5. DTA (blue) and TGA (red) spectra of the hybrid silicon/zirconium sol-gel material. (For interpretation of the references to colour in this figure legend, the reader is referred to the web version of this article.)

UV-Visible absorption spectra of the dye will be assigned to the effect of the sol-gel structure and not to the degradation of the dye.

Fig. 5 shows both the DTA and TGA curves of hybrid silicon/zirconium sol-gel material. Here, the DTA curve shows an endothermic band centred at $40{ }^{\circ} \mathrm{C}$, and three exothermic bands located at 185,220 and $250^{\circ} \mathrm{C}$. The endothermic band represents the evaporation of the solvent present in the employed precursors and formed during the sol-gel hydrolysis and condensation reactions. The exothermic bands represent the formation of irreversible bonds in the systems which can definitely result from condensations reactions (formation of irreversible inorganic $\mathrm{Si}-\mathrm{O}-\mathrm{Si}$ and $\mathrm{Si}-\mathrm{O}-\mathrm{Zr}$ bonds) taking place between the inorganic groups of the materials and the subsequent release of water and solvent. This is confirmed by the slight change in the weight of the material (around $15 \%$ ) from 100 to $300^{\circ} \mathrm{C}$. Most significantly, the increase of the temperature from 100 to $150{ }^{\circ} \mathrm{C}$ provokes a decrease of only $6 \%$ of the total weight of the material, which is again attributed to the sol-gel condensation reactions, confirming a change in the structure of the hybrid network without provoking its degradation.

\subsection{Structural characterisation of the coatings}

Fig. 6(a-c) shows the FTIR spectra of the three series of materials cured at 100,120 and $150{ }^{\circ} \mathrm{C}$. All absorption bands were ascribed based on results reported in closely related studies in the field [14-16]. In the first instance, all spectra show the presence of the same chemical vibrations due to the employment of the same precursors and materials preparation, the difference being in the ratio of the precursors and in the curing of the coatings. The broad band located at $800-1100 \mathrm{~cm}^{-1}$ is characteristic 

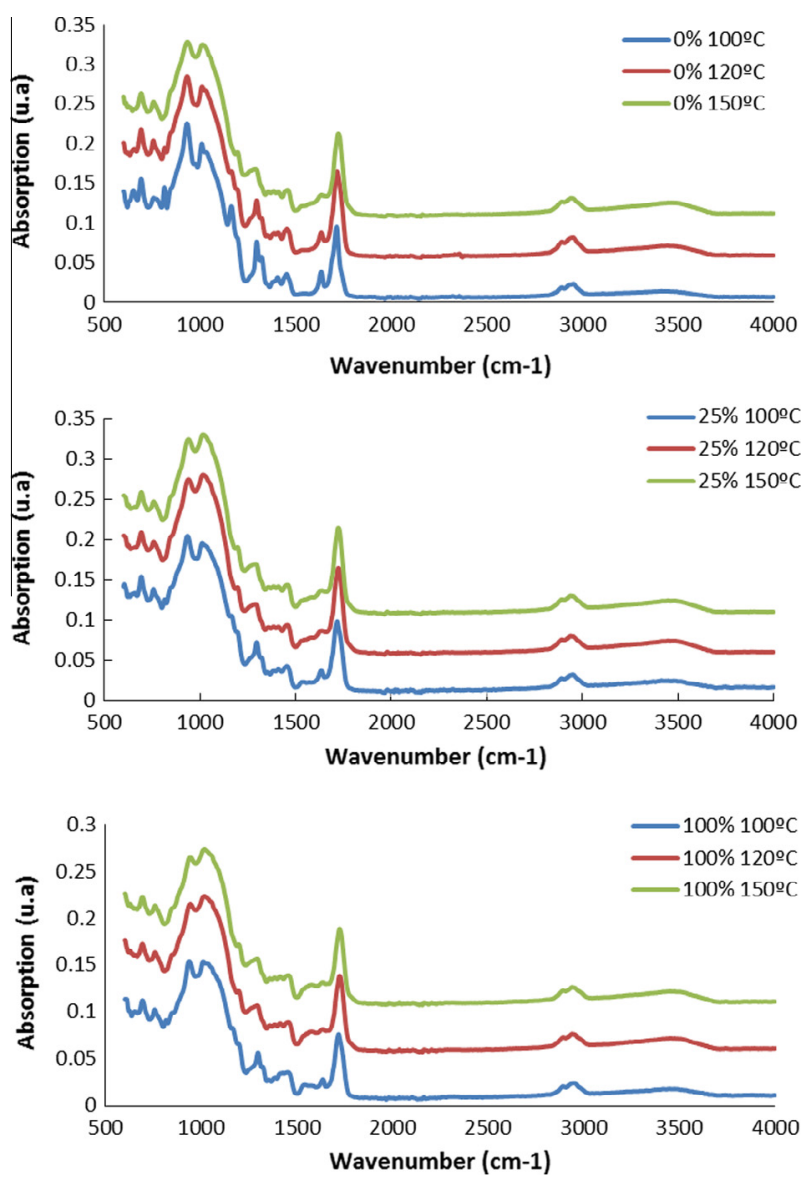

Fig. 6. Ftir spectra of coatings A (a), B (b) and C (c) cured 100,120 and $150{ }^{\circ} \mathrm{C}$.

of the silicate network resulting here mainly from the superimposition of the silanol $\left(\mathrm{Si}-\mathrm{OH}, 950 \mathrm{~cm}^{-1}\right)$ stretches, $\mathrm{Si}-\mathrm{O}-\mathrm{Si}$ and $\mathrm{Si}-\mathrm{O}-\mathrm{Zr}$ vibrations $\left(1000-1100 \mathrm{~cm}^{-1}\right)$. The band observed at $1170 \mathrm{~cm}^{-1}$ symbolises the stretching of the $\mathrm{Si}-\mathrm{O}-\mathrm{C}$ contained in the methoxy-silane groups of the MAPTMS. The $\mathrm{Zr}-\mathrm{OH}$ and $\mathrm{Zr}-\mathrm{O}-\mathrm{C}$ bonds composing the zirconium complex are located in the region $1300-1650 \mathrm{~cm}^{-1}$. The bands located at $1730,2800-$ 3000 and $3200-3600 \mathrm{~cm}^{-1}$ are due to the $\mathrm{C}=\mathrm{O}$ (stretching), $\mathrm{C}-\mathrm{H}$ (stretching) and residual $\mathrm{Si}-\mathrm{OH}$ and $\mathrm{Zr}-\mathrm{OH}$ groups (stretching), respectively.

For the three series of materials, as the curing temperature is increased a similar tendency can be observed in the change of the peculiar groups of the silicate and zirconium systems. The intensities of the vibration bands for the $\mathrm{Si}-\mathrm{OH}$ and $\mathrm{Si}-\mathrm{O}-\mathrm{C}$, representing the non-condensed silicate species are seen to decrease for the benefit of the more silicate condensed species ( $\mathrm{Si}-\mathrm{O}-\mathrm{Si}$ and $\mathrm{Si}-\mathrm{O}-\mathrm{Zr}$ ), located between 1000 and $1100 \mathrm{~cm}^{-1}$. Moreover, the intensities of the chemical vibrations due to the zirconium complex located at $1300-1650 \mathrm{~cm}^{-1}$ are clearly seen to all decrease for the benefit of the $\mathrm{Si}-\mathrm{O}-\mathrm{Zr}$ bonds.

In order to quantify the evolution of the non-condensed and condensed species, deconvolution of the infrared spectra was undertaken in the range $800-1250 \mathrm{~cm}^{-1}$. This was performed by applying a linear regression and modelling the sub-absorption bands employing Gaussian curves [17], as shown in Fig. 7 (as all materials exhibited the same behaviour only deconvolution of material A is presented). The fitting matched the experimental data at $97-99 \%$. An important aspect of this study is to quantify the evolution of the $\mathrm{Si}-\mathrm{OH} /(\mathrm{Si}-\mathrm{O}-\mathrm{Si}+\mathrm{Si}-\mathrm{O}-\mathrm{Zr})$ ratio against the temperature for all materials. The calculations of these ratios based on the contribution of each of the bands are presented in Table 1.
For all materials, this ratio is found to decrease as the temperature increases. From 100 to $120^{\circ} \mathrm{C}$, the most significant change is found for materials $B$ and $C$ with a decrease of $16 \%$, while it was found to be close to $10 \%$ for material A. At $150{ }^{\circ} \mathrm{C}$, this ratio is found to be $27.3 \%, 29.2 \%$ and $31.6 \%$ for materials A, B and C, respectively. Overall, the curing temperature provokes a similar tendency on all materials but seems to be slightly more significant for material $\mathrm{C}$ at the highest applied temperature, probably due to the more connected network inherent to the higher reactivity of this system (minimum chelation degree amongst the three materials). Furthermore, the deconvolution of these spectra shows that the increase of the curing temperature also decreases the $\mathrm{Si}-\mathrm{O}-\mathrm{C}$ vibration at $1170 \mathrm{~cm}^{-1}$, which disappears at $150^{\circ} \mathrm{C}$. This indicates that the residual methoxide groups present in the materials also participate to the condensation process by polycondensation reactions with neighbouring $\mathrm{Si}-\mathrm{OH}$ and $\mathrm{Zr}-\mathrm{OH}$ groups. Therefore, these results suggest that the increase of the curing temperature enables the formation of chemical bonds with a higher degree of condensation, thus clearly confirming the occurrence of condensation reactions taking place between the silicate-based moieties themselves and with the zirconium-based moieties to form denser particles. Importantly, this result would confirm that the curing process that increases the condensation of the materials may also increase the connectivity between the organic dye and the sol-gel matrices.

\subsection{Photophysical properties of trypan blue}

\subsubsection{Effect of the sol on the absorption of the dye}

UV-Visible absorption spectrum of TB dispersed in isopropanol is shown in Fig. 8. One can see that the dye exhibits one large band composed of two superimposed bands located in the region 400$600 \mathrm{~nm}$ and a large absorption extending from around $400 \mathrm{~nm}$ up to $300 \mathrm{~nm}$. TB is a symmetrical molecule that contains unsaturated and conjugated $\mathrm{C}=\mathrm{C}$ and $\mathrm{N}=\mathrm{N}$ bonds, in addition to amine, hydroxyl and sulfonyl groups. Therefore, the two domain of absorption, above and below $400 \mathrm{~nm}$, can be attributed to the $\mathrm{n} \rightarrow \pi^{*}$ electronic transitions due to the presence of amine, hydroxyl and sulfonyl groups, and to the $\pi \rightarrow \pi^{*}$ electronic transitions of the unsaturated $\mathrm{C}=\mathrm{C}$ and $\mathrm{N}=\mathrm{N}$ bonds of the conjugated aromatic groups, respectively.

The effect of the three developed sol-gel materials on the UVVisible absorption of TB in the liquid state is shown in Fig. 9. One can observe that both absorption bands in the spectrum of the pure dye are present in those of all sol-gels. However, the presence of any sol-gel material provokes a $4 \mathrm{~nm}$ red shift of the bands initially located at 574 and $607 \mathrm{~nm}$, but more significantly the intensity of the absorption of these bands increases with the decrease of the chelation degree, while those of the bands located below $400 \mathrm{~nm}$ (around $325 \mathrm{~nm}$ ) remain almost unchanged. These results mean that the $n \rightarrow \pi^{*}$ electronic transitions are favoured by the decrease of the chelation degree while the $\pi \rightarrow \pi^{*}$ electronic transitions are not affected. These observations suggest that the sol-gel matrix is not only acting as a dispersing system for the dye, but also interactions at the molecular level between the dye and the host matrices are occurring and modifying the local environment of the dye structure, thus explaining the modification of their spectral absorption. As the intensities of the $n \rightarrow \pi^{*}$ electronic transitions is decreasing with the increase of the condensation of the material, this means that the chemical groups responsible for these electronic transition are more affected by the less condensed materials. This clearly indicates that the reactive centres of the dyes towards the sol-gel matrices are those responsible for these $n \rightarrow \pi^{*}$ electronic transitions namely, the amine, hydroxyl and sulfonyl groups. If it is difficult to distinguish which one of these groups is reacting prevalently with the sol-gel matrix, it is however very likely that 

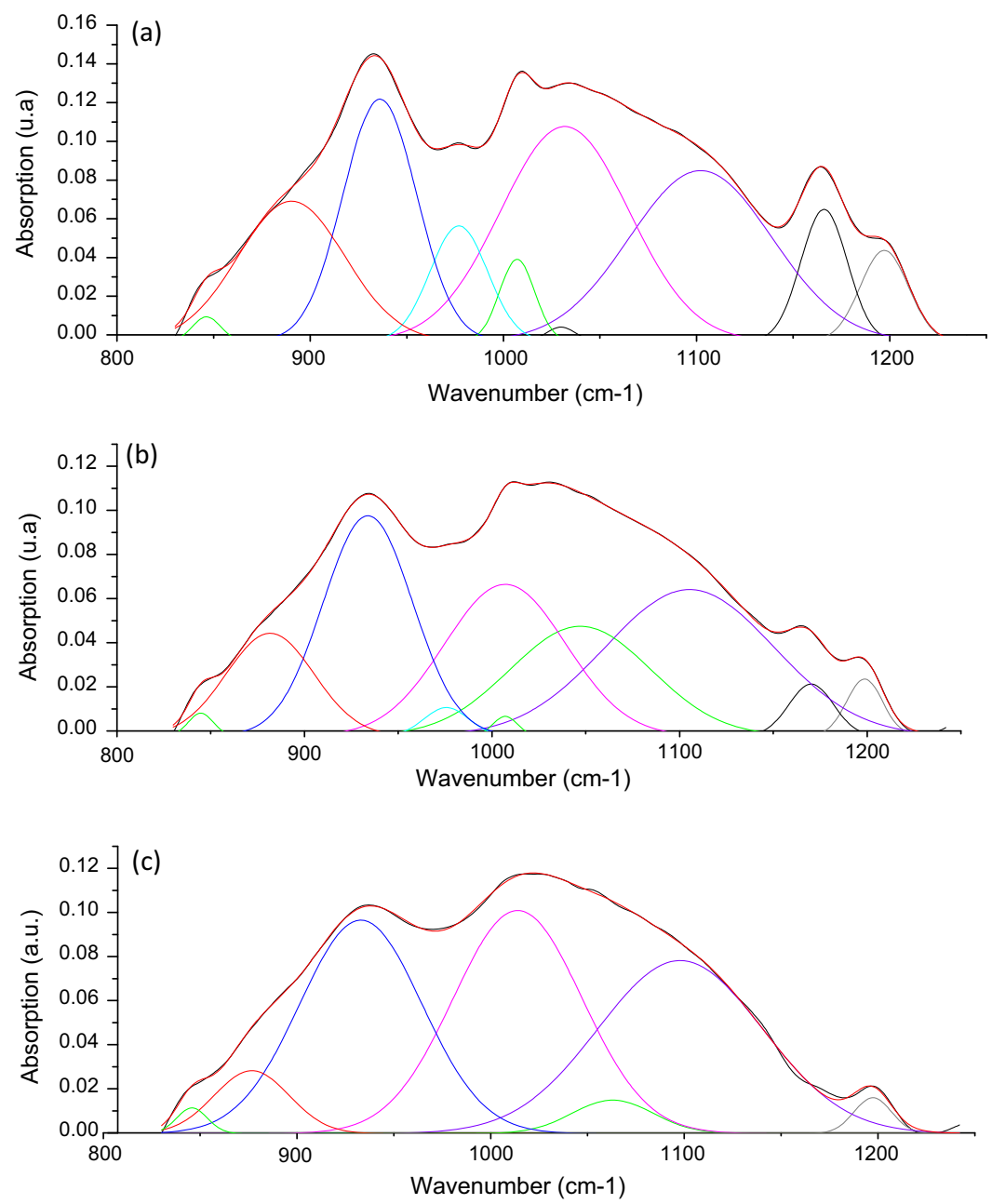

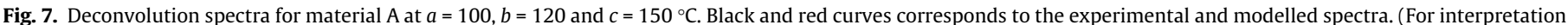
of the references to colour in this figure legend, the reader is referred to the web version of this article.)

Table 1

Calculations of $\mathrm{Si}-\mathrm{OH} /(\mathrm{Si}-\mathrm{O}-\mathrm{Si}+\mathrm{Si}-\mathrm{O}-\mathrm{Zr})$ ratio for all materials.

\begin{tabular}{lll}
\hline Materials-temperatures $\left({ }^{\circ} \mathrm{C}\right)$ & $\mathrm{Si}-\mathrm{OH} /(\mathrm{Si}-\mathrm{O}-\mathrm{Si}+\mathrm{Si}-\mathrm{O}-\mathrm{Zr})$ & \% Change \\
\hline Material A - 100 & 72.6 & - \\
Material A - 120 & 65.6 & 9.7 \\
Material A - 150 & 52.8 & 27.3 \\
Material B - 100 & 68.2 & - \\
Material B - 120 & 57.5 & 15.7 \\
Material B - 150 & 48.3 & 29.2 \\
Material C - 100 & 62.6 & - \\
Material C - 120 & 52.7 & 15.8 \\
Material C - 150 & 42.8 & 31.6 \\
\hline
\end{tabular}

the only group within the sol-gel material that can react with these groups is the $\mathrm{Zr}$ atom. Based on this, it is proposed that the difference in reactivity between the three sol-gel formulations relies on the accessibility of the $\mathrm{Zr}$ atom by the dye. Because of the large molecular size of the dye, it is unlikely that two or more reactive groups could directly bind to the sol-gel matrix in the liquid phase. Therefore, the proposed formed molecular system is sketched in Fig. 10 (supposing that the amine function would be utilised preferentially). The proposed model is in good agreement with the observed increase of the absorption bands below $400 \mathrm{~nm}$ as the formation of a covalent bond between the $\mathrm{Zr}$ and the amine would result in a greater electron delocalization reinforced by the electron affinity of the $\mathrm{Zr}$ atom.
3.4.2. Effect of the sol-gel transition and curing temperature on the absorption of the dye

The effect of curing temperature of coatings fabricated from sol-gel A on the absorption of TB is shown in Fig. 11. It can be seen that whatever the curing temperature, negligible absorption is observed above $500 \mathrm{~nm}$ for TB incorporated within sol-gel A, suggesting that the $\mathrm{n} \rightarrow \pi^{*}$ electronic transition is quenched. However, the increase of the curing temperature shows clear differences in

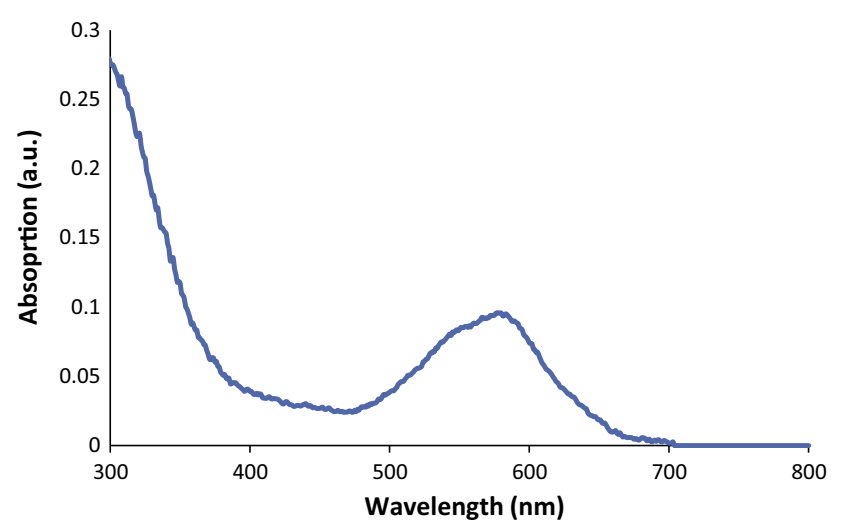

Fig. 8. Absorbance spectra of TB dispersed in 2-propanol. 


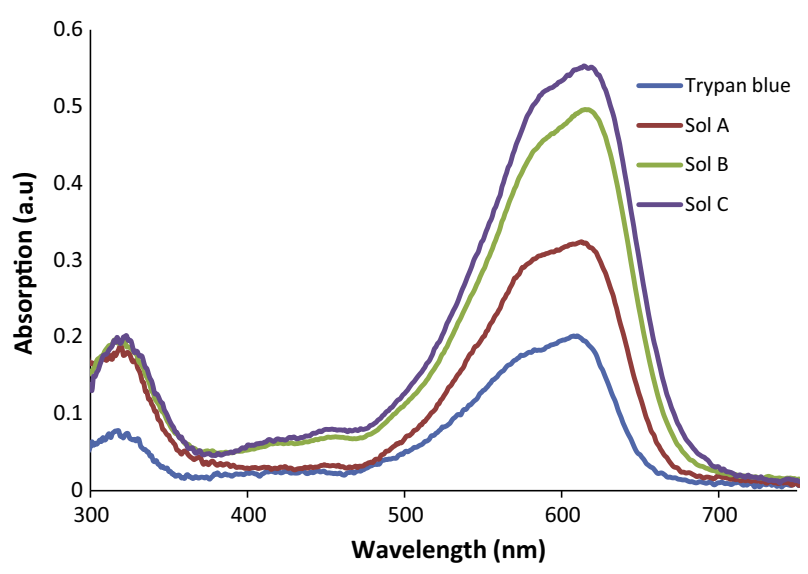

Fig. 9. UV-Visible absorption spectra of tripan blue dispersed in liquid sol-gels A, B and $\mathrm{C}$.

the absorption bands located below $400 \mathrm{~nm}$. At $100{ }^{\circ} \mathrm{C}$, a single large absorption band with a FWHM (Full Width at Half Maximum) $\sim 70 \mathrm{~nm}$ is centred at $230 \mathrm{~nm}$. At $120^{\circ} \mathrm{C}$, this band undergoes a red shift to $295 \mathrm{~nm}$. At $150{ }^{\circ} \mathrm{C}$, two clear bands centred at 230 and $300 \mathrm{~nm}$ are observed. Interestingly, these two bands coincide with the addition of the bands observed for coatings cured at 100 and $120^{\circ} \mathrm{C}$. The progressive red shift observed with the increase of the curing temperature suggests that $\pi \rightarrow \pi^{*}$ electron transitions are favoured. From a structural standpoint, the increase of the curing temperature provokes the increase of the condensation processes, thus resulting in more condensed particles. This densification process brings the dye closer together to the sol-gel matrix and enables the formation of chemical bonds that are not permitted or fully permitted in the liquid phase. From these results, unlike the dye dispersed in the liquid sol-gels, in sol-gel A and whatever the curing temperature, it is very likely that the dye is connected to the sol-gel matrix via at least two chemical bonds, as proposed in Fig. 12.

As shown in Fig. 13, sol-gel B exhibits a very similar effect on the dye absorption as sol-gel A with the exception of the remaining absorption band in the $600 \mathrm{~nm}$ region, originally present in the liquid state, for all curing temperatures. However, this band is clearly seen to decrease in its intensity and its $\lambda_{\max }$ progressively undergoing a blue shift, as the curing temperature increases. Oppositely, the high absorption bands located below $400 \mathrm{~nm}$ are seen to undergo a red shift for the transition $100-120^{\circ} \mathrm{C}$ $(+\sim 30 \mathrm{~nm})$, and a stagnation of the $\lambda_{\max }$ for the transition 120$150^{\circ} \mathrm{C}$. However, it shows an increase by a factor of 3 in its intensity. This demonstrates that the increase of the curing temperature favours the electron transition of the high absorbing band and suggests that the dye is brought closer together to the sol-gel matrix. The difference between sol-gel A and B on the effect of the absorption band around $600 \mathrm{~nm}$ is explained by the structure of the developed nanoparticles. The decrease by four of the ligand

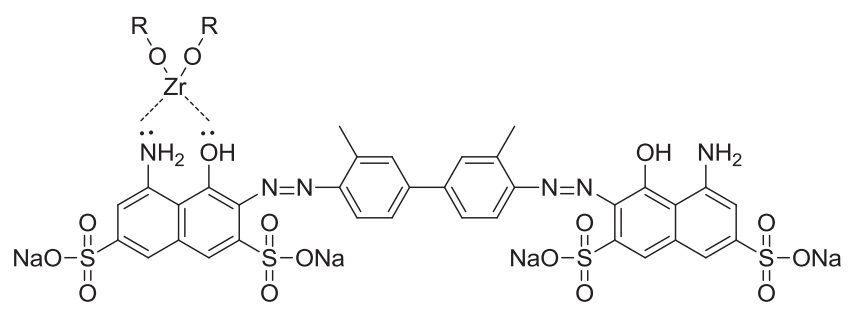

Fig. 10. Chemical structure of TB formed with sol-gel A, B and C in the liquid phase.

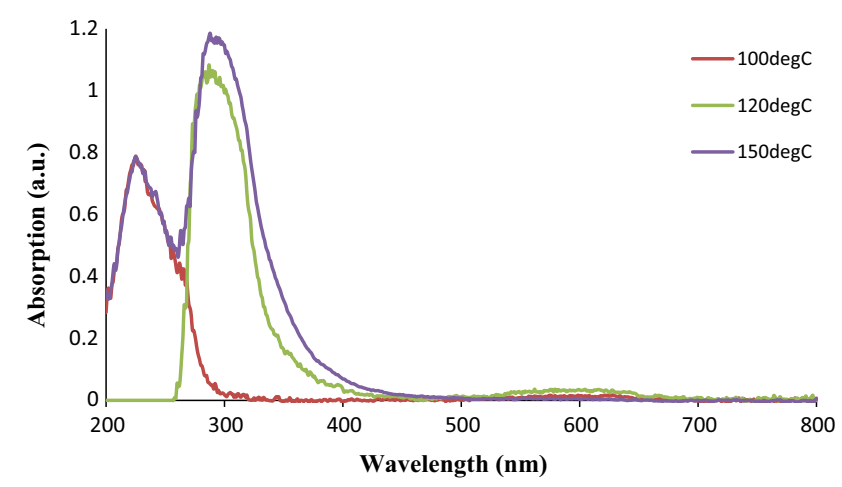

Fig. 11. UV-Visible absorption spectra of sol-gel A coatings cured at 100,120 and $150^{\circ} \mathrm{C}$.

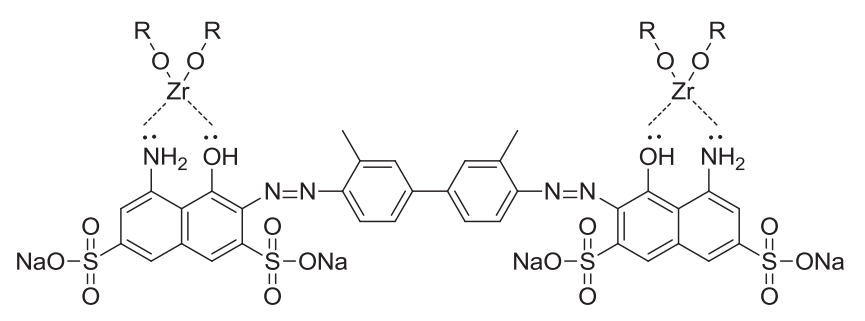

Fig. 12. Chemical structure of $T B$ formed with sol-gel $A, B$ and $C$ in the solid phase.

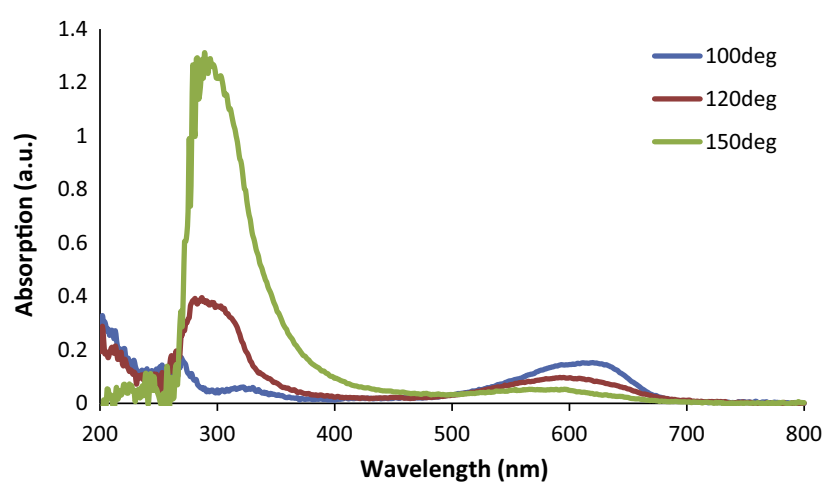

Fig. 13. UV-Visible absorption spectra of sol-gel B coatings cured at 100,120 and $150^{\circ} \mathrm{C}$.

concentration has been found to provoke the increase of the nanoparticle size (Fig. 3), the consequence of which is the creation of a more condensed sol-gel system where the local environment of the $\mathrm{Zr}$ atom is mainly composed of zirconium oxide bonds. In theory, in sol-gel B, 75\% of the $\mathrm{Zr}$ atoms are free to fully condense to form a polymeric 3D zirconium oxide network. Therefore, the natural binding of the dye to the $\mathrm{Zr}$ atom, observed in sol-gel $\mathrm{A}$, is limited by the more condensed structure of the $\mathrm{Zr}$ atom in solgel $\mathrm{B}$. However, the change of the absorption bands, when increasing the curing temperature, increases the condensation of the nanoparticles and forces the dye to get closer to the $\mathrm{Zr}$ atom, the consequence of which is a binding between the two species. However, unlike the behaviour observed for the dye in sol-gel A, the outstanding absorption around $600 \mathrm{~nm}$ suggest that the dye still contains amino, hydroxyl and sulfonyl groups in their original form Therefore, the proposed structure of the dye is an intermediate configuration between the molecular designs proposed in Figs. 10 and 12 .

This explanation is further confirmed by the effect of sol-gel $\mathrm{C}$ on the absorption of the dye, as shown in Fig. 14. First, the intensity 


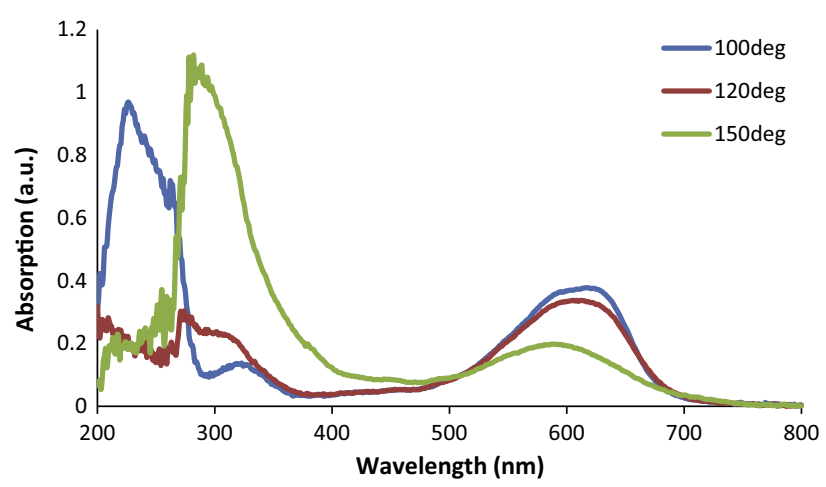

Fig. 14. UV-Visible absorption spectra of sol-gel C coatings cured at 100,120 and $150{ }^{\circ} \mathrm{C}$.

of the absorption band around $600 \mathrm{~nm}$ is greater than those observed for sol-gel B, whatever the curing temperature $(53 \%$, $33 \%$ and $25 \%$ for the coatings cured at 100,120 and $150{ }^{\circ} \mathrm{C}$, respectively). Second, the ratio of the $\lambda_{\max }$ intensities of the bands around $600 \mathrm{~nm}$ and below $400 \mathrm{~nm}$ is seen to increase by a factor 5 between the two systems for the highest curing temperature. Furthermore, the coating cured at $100^{\circ} \mathrm{C}$ exhibits a very similar spectrum to the one recorded for the pure dye, suggesting that no interaction between the two species is taking place. Based on these observations, it is evident that the degree of connectivity of the dye to the sol-gel matrix is lower than those observed with sol-gel A and B, and the molecular structure of the formed system tending towards the design proposed in Fig. 9. This is essentially due to the structure of the final sol-gel nanoparticles which are denser than those formed with sol-gel A and B and more importantly, where the $\mathrm{Zr}$ atom is fully involved in the formation of covalent oxide bonds, with limited access of the dye to bind with the $d$ free orbitals of the metal transition.

\section{Conclusion}

The work reported in this paper highlights two relevant results in the sol-gel chemistry and in the optical properties of a typical organic dye. Firstly, it is shown the possibility to control the degree of condensation of sol-gel nanostructures by altering the degree of chelation in transition-metal-based hybrid organic-inorganic materials prepared by the sol-gel process. By progressively decreasing the chelation degree of the transition metal, increase of the size of the nanoparticle has been identified by TEM analyses. This is attributed to the increase of the reactivity to hydrolysis and condensation reactions enabled by the increased number of reactive sites in the transition metal. Interestingly, it is shown that the half chelated systems exhibit particles with sizes comprised between 5 and $10 \mathrm{~nm}$, while the size of the particles prepared with the quarterly and non-chelated systems are up to $200 \mathrm{~nm}$ and of micron scale, respectively. Secondly, the optical properties of a typical organic dye, tripan blue, were investigated by incorporating it in the different sol-gel materials and the UV-Visible spectra recorded in both liquid and solid state (as coatings). In addition to this, the effect of the curing temperature of the prepared coatings has also been performed. These studies revealed two relevant results. The sol-gel morphology plays a critical role in the optical properties of the dye. The effect of the sol-gel host matrix onto the optical properties of the dye is attributed to the steric hindrance of the nanostructures, themselves intimately dependant on the reactivity of the transition metal. For instance, the less condensed system (material A) shows the highest reactivity with the dye (probably by forming covalent bonds between the $\mathrm{Zr}$ atom and either the amine, hydroxyl or sulfonyl groups of the dye) while the more condensed system (material C) exhibits limited interaction with the dye, symbolised by a significant change or quasi-unchanged UV-Visible spectrum, respectively. It is shown that the increase of the condensation degree of the sol-gel coatings by heat-curing can dramatically alter the optical properties of the dye especially for the most condensed sol-gel systems (materials $\mathrm{B}$ and $\mathrm{C}$ ). This has been attributed to proximity effects enabled by the increase of the materials densities.

The results reported here aim to provide a better understanding of the role of the structure of the materials onto the optical properties of a typical organic dye and suggest that the structure of the host matrix along with applied curing process have to be fully considered and assessed in the choice of organic dyes and for the aimed applications.

\section{References}

[1] (A) L.F. Koberlein, US 2524811 A, 1950.;

(B) P.V. Kitchloo, R.A. Sallavanti, WO 2001077212 B1, 2002.;

(C) H. Lichtenstein, G. Ittmann, E. Albrecht, CA 2496068 A1, 2004

[2] (A) R.J. Kaiser, G.W. Preuninger, EP 0557115 A1, 1993.;

(B) M. Inuzuka, WO 2002071108 A1, 2002.

[3] (A) C. Gallo, C. Gallo, US 20060116442 A1, 2006.

(B) C.S. Bramley, EP 1400574 A1, 2004.;

(C) G. Hovorka, WO 2008027097 A3, 2008.

[4] (A) K.S. Chuang, US 20120141398 A1, 2012 ;

(B) M. Beyer, D. Teichmuller, US 8152860 B2, 2012.;

(C) L. Theisen, US 7022331 B2, 2006.

[5] (A) A.P. Schäfer, Dye Lasers, 2nd ed., Springer-Verlag, Berlin, 1990; B) T.W. Hänsch, Appl. Opt. 11 (1972) 895;

(C) F.J. Duarte, J.A. Piper, Opt. Commun. 35 (1980) 100

[6] (A) J. Yamada, R.M. Dana, C. Sotozono, S. Kinoshita, Exp. Eye Res. 76 (2003) 161 ;

(B) M.S. Ögüt, T. Bavbek, H. Kazokoglu, Acta Ophthalmologica 71 (1993) 69.

[7] (A) D.S. Mull, U.S. Geological Survey, Report 92-4195.;

(B) S. Martin, I. Naydenova, V. Toal, US 8383294 B2 2013.;

(C) V. Farrelly, I. Naydenova, S. Martin, V. Toal, WO 2008004203 A2, 2008.

[8] (A) H. Bae, H. Jung, Y. Lee, C. Park, WO 2012015233 A9, 2012.; (C) J. Shi, E. Forsythe, D. Morton, US 20050212409 A1, 2005.

[9] C. Sanchez, J. Livage, M. Henry, F. Babonneau, J. Non-Cryst. Sol. 100 (1988) 6576.

[10] R. Nass, H. Schmidt, J. Non-Cryst. Solids 121 (1990) 329-333.

[11] M. Oubaha, M. Smaihi, P. Etienne, P. Coudray, Y. Moreau, J. Non-Cryst. Sol. 318 (2003) 305-313.

[12] M. Oubaha, M. Dubois, B. Murphy, P. Etienne, J. Sol-Gel Sci. Technol. 38 (2006) 111-119, http://dx.doi.org/10.1007/s10971-006-7114-7.

[13] Mohamed Oubaha, Andrew Kavanagh, Arnaud Gorin, Gabija Bickauskaite, Robert Byrne, Maria Farsari, Richard Winfield, Dermot Diamond, Colette McDonagh, Robert Copperwhite, J. Mater. Chem. 22 (2012) 10552.

[14] M. Rosario Elvira, M. Alejandra Mazo, Aitana Tamayo, Fausto Rubio, Juan Rubio, Jose Luis Oteo, J. Chem. Eng. 7 (2013) 120-131.

[15] David M. Pickup, Gavin Mountjoy, Graham W. Wallidge, Robert J. Newport, Mark E. Smith, Phys. Chem. Chem. Phys. 1 (1999) 2527.

[16] P.C. Rajath Varma, John Colreavy, John Cassidy, Mohamed Oubaha, Brendan Duffy, Colette McDonagh, Prog. Org. Coat. 66 (2009) 406.

[17] M. Oubaha, P. Etienne, S. Calas, R. Sempere, J.M. Nedelec, Y. Moreau, J. NonCryst. Sol. 351 (2005) 2122-2128. 